\title{
Do pessimists report worse outcomes after total hip arthroplasty?
}

\author{
Jasvinder A. Singh ${ }^{1,4,5,6^{*}}$, Robert C. Colligan², Megan M. O'Byrne ${ }^{3}$ and David G. Lewallen ${ }^{1}$
}

\begin{abstract}
Background: Seligman's theory of causal attribution predicts that patients with a pessimistic explanatory style will have less favorable health outcomes. We investigated this hypothesis using self-reported hip pain and hip function 2- years after total hip arthroplasty (THA).

Methods: Most THA patients had completed the Minnesota Multiphasic Personality Inventory (MMPI) during their usual clinical care long before THA (median, 14.7 to 16.6 years). Scores from the MMPI Optimism-Pessimism (PSM) scale were used to categorize patients as pessimistic (t-score $>60$ ) or non-pessimistic (t score $\leq 60$ ). Outcomes were self-reported: (a) moderate-severe pain, (b) absence of "much better" improvement compared to preoperative hip function, and (c) moderate-severe activity limitation. Multivariable logistic regression was adjusted for gender, age and other covariates. Odds ratios (OR) with $95 \%$ confidence intervals (Cl) are presented.

Results: We identified 507 patients with 565 primary THAs with an MMPI prior to primary THA, of whom 441 patients with 488 primary THAs had responded to hip pain and function follow-up surveys at 2-years post-surgery. Similarly, 202 patients with 235 revision THAs had an MMPI prior to surgery, of whom 172 patients with 196 revision THAs completed 2-year surveys. Among those with primary THA, pessimists reported (a) a non-significant trend toward more moderate-severe pain at 2-years with OR (95\% Cl; $p$-value), 2.16 (0.90, 5.20; $p=0.08$; reference, none-mild pain), (b) no significant difference for absence of "much better" improvement in hip function at 2-years, 1.87 (0.77, 4.52; $p=0.16$; reference, much better hip function); and (c) significantly higher rate of moderate-severe activity limitation at 2-years, $2.90(1.25,6.70 ; p=0.01)$. Among revision THA cohort, pessimists reported no significant differences from non-pessimists in moderate-severe pain, improvement in hip function or moderate-severe functional limitation at 2-years.
\end{abstract}

Conclusions: A pessimistic explanatory style was associated with moderate-severe activity limitation and a nonsignificant trend towards moderate-severe pain post-THA.

Keywords: Pessimism, Total hip arthroplasty, THA, Outcomes, Psychological risk factor, Pessimistic style

\section{Background}

Total hip arthroplasty (THA) is a successful surgical procedure. THA is associated with significantly decreased pain, improved hip function, and better overall quality of life $[1,2]$. Some patients have suboptimal pain and function outcomes following THA. A distressed psychological state around the time of surgery, can negatively impact outcomes after THA [3]. Psychological

\footnotetext{
* Correspondence: Jasvinder.md@gmail.com

'Department of Orthopedic Surgery, Mayo Clinic, Rochester, MN, USA

${ }^{4}$ Rheumatology Section, Medicine Service, VA Medical Center, Minneapolis, MN, USA

Full list of author information is available at the end of the article
}

stressors can be broadly classified in two ways: first, as emotional states that fluctuate over time (e.g., depression, anxiety) and second, psychological traits that are relatively stable and chronic (such as a pessimistic explanatory style).

In our recent study of patients undergoing total knee arthroplasty (TKA), we found that a pessimistic explanatory style, determined years before the TKA, was associated with increased pain and decreased function at follow up, two years after surgery [4]. Studies over 30-years found that pessimistic explanatory style was significantly associated with increased mortality [5] and poorer self-reported quality of life [6] in general medical clinic cohorts. Thus, a 
pessimistic explanatory style, as a pre-existing trait, a psychological risk factor, can negatively impact important outcomes in medical and surgical patients. It is not known if certain, pre-existing, psychological characteristics, such as optimism or pessimism, affect outcomes after THA.

According to Seligman's theory, people with pessimistic style attribute the causes of adverse events in their lives to themselves (i.e., an internal explanation, "It's me..."), carry the expectation that the condition will persist (i.e., a stable explanation, "...happened again, as usual..."), and believe that it will affect other aspects of their life (a global explanation, "...and now... I'll never get to.."). The converse characterizes an "optimistic" explanatory style [7-9]. Pessimistic style is associated with higher risks of poorer physical health, depression and lower academic accomplishments [10].

To our knowledge there are no studies that have determined if pessimistic explanatory style is associated with poorer outcomes after THA, except one study. The study found that optimism assessed on Life Orientation test immediately pre-THA was associated with shortterm functional outcomes in the first 3 months after surgery [11]; however, the study did not adjust for depression, a factor associated with poor THA outcomes. The impact of pessimistic explanatory style on intermediateterm outcomes post-THA is not known. Conversely, it is not known if THA patients with poor outcomes differ in their explanatory styles assessed a decade or two prior to their surgery. In this research, our objectives were to assess whether pessimistic explanatory style is independently associated with poor outcomes of pain, activity limitations and the lack of improvement in hip joint function after primary or revision THA.

\section{Methods}

\section{Study sample}

The study cohort consisted of patients who had undergone primary or revision THA between 1993 and 2005 at Mayo Clinic in Rochester, MN, and completed the Mayo Hip Survey, a validated pain/function questionnaire with construct validity and reliability $[12,13]$, at 2 -years postsurgery and a Minnesota Multiphasic Personality Inventory (MMPI) questionnaire at any time prior to their index THA. Surveys within six months either before or after the specific time point post-operatively were used for that time point. Patients with revision surgery prior to the 2-year mark were assessed prior to revision and that assessment was used as their 2-year survey. Patient-reported outcomes (PROs) of pain, function and activity limitation were derived from Mayo Hip Survey mailed to the patients or administered in the clinic during follow-up visits, as a part of regular clinical follow up. The questionnaire was administered on the telephone by trained Joint Registry staff to patients not responding to mailed survey and/ or not returning for clinic follow-up. All MMPIs given at Mayo Clinic are stored electronically in a central database. The MMPI was given to patients as part of their routine care at Mayo Clinic, or as a result of participating in a research study; however, these THA patients were not specifically targeted to receive the MMPI. The overlap of the THA patients with follow-up Mayo Hip Surveys and the MMPI database comprised our sample. The Institutional Review Board at the Mayo Clinic approved the study, and waived the need for written informed consent for this study. We followed the Strengthening of Reporting in Observational studies in Epidemiology (STROBE) statement to describe this study [14].

\section{Predictor of interest: pessimism on MMPI profile}

The original MMPI consisted of 550 unique true/false items pertaining to thoughts, feelings, attitudes, physical symptoms, emotional symptoms, and previous life experiences. The MMPI and its current revision, the MMPI2 [15] are among the most widely used and thoroughly researched self-reported measures of personality assessment to date [16].

We used empirical approaches to assess the Optimism-Pessimism (PSM) scale of the MMPI [17], our main independent variable of interest. T-scores for the MMPI have been standardized to have a mean of 50 and standard deviation of 10 . Recent studies have used $\mathrm{t}$-scores above 60 (which is 50 plus one standard deviation) on a bi-directional scale of PSM using the MMPI item pool $[18,19]$ to indicate the pessimistic explanatory style. As previously $[5,6]$, we classified patients into two categories based on PSM scale scores preceding the THA as pessimists (T-score $>60$ ) or non-pessimists ( $\mathrm{T}$ score $\leq 60)$. MMPI scores have high internal consistency with Cronbach's alpha of 0.85 for good events and 0.95 for bad events, reliability of 0.94 on linear composite reliability formula, and test-retest reliability of 0.90 [18]. MMPI scores have been shown to be stable with a correlation of 0.54 for negative events over 52 years [20].

\section{Outcomes of interest}

We assessed three PROs, hip pain, improvement in hip function and activity limitation, as outcomes of interest. Index hip pain was assessed by a single question- "How much pain do you have in your hip that was operated?" Moderate or severe pain response were combined into moderate-severe pain and no or mild pain responses constituting the reference group.

Self reported improvement in hip function was assessed with a single question- "Compared to your condition before your hip surgery, how would you rate your hip function? We compared patients reporting "somewhat better, same or worse hip function" hip function with those in the reference category comprising "much 
better hip function". The rationale for this categorization was that THA is an extremely successful surgery and most patients aim to achieve a much better hip function compared to preoperative status for this, mainly, elective procedure.

We categorized the responses to limitations in seven activities as follows: (1) walking, climbing stairs, sitting, rising from chair into 'no', 'mild,' 'moderate' or 'severe' limitation for each activity; and (2) three activities including putting on shoes/socks, picking up objects from the floor, getting in/out of the car into none, moderate and severe limitation, due to no response category corresponding to mild limitation. Overall moderate-severe ADL limitation was defined as the moderate or severe limitation in $\geq 3$ activities, as previously [21, 22].

\section{Covariates/confounders}

Potential confounders i.e., gender and age $(\leq 60,61-70$, $>70$ years) were included in the multivariable analyses of these PROs, due to their known previous associations with these outcomes in THA population [22-24]. In addition, multivariable analyses included other covariates, which could potentially impact pain/function outcomes as long as the number of events allowed inclusion of these variables (at least 10 events per variable): depression score (scale 2 (D) from the MMPI), comorbidity, median household income (a measure of socioeconomic level and an indirect measure of education level), preoperative pain and preoperative function.

\section{Statistical analyses}

The association of pessimistic explanatory style with each of the three PROs was assessed in univariate analyses, separately in primary and revision THA cohorts, at 2-years. Multivariable logistic regression analyses adjusted for the potential confounders including age and gender. All multivariable-adjusted analyses used a generalized estimating equations (GEE) approach adjusting the standard errors for the within person correlation due to bilateral hip replacement and/or multiple operations on the same hip. Logistic regression analysis was used to determine which types of patients were more likely to have provided MMPI data, by comparing characteristics including age, gender, etc. Odds ratios (OR) with $95 \%$ confidence intervals $(\mathrm{CI})$ are reported, $p$-values $<0.05$ were considered significant, and $p$-values between 0.05 and 0.10 were considered a trend toward statistical significance. Analyses were performed using SAS 9.3 (Cary, NC) and Stata version 10 (College Station, TX).

\section{Results}

Demographics of the study cohort and non-response bias We studied 488 patients with primary THA and 196 with revision THA who completed MMPIs and who had responded to post-THA pain and function-activity questionnaires at 2-years post-surgery. Median time from the time of MMPI completion to THA exceeded 14 years for both primary and revision THA cohorts (Table 1).

For the primary THA 2-year follow-up cohort, mean age at surgery was 67.4 years, $43 \%$ were men, $25 \%$ had normal BMI of $\leq 25$ and the underlying diagnosis was osteoarthritis in $84 \%$ (Table 1). Characteristics of 2-year revision THA cohort were similar and are summarized in Table 1.

\section{Patients with an MMPI}

Patients in the primary 2-year follow up group were more likely to have had an MMPI if they were female, older, had higher comorbidity ASA class or household income, or lived closer to the medical center (Appendix 1). There were no significant effects of operative diagnosis or BMI. Revision THA 2-year cohort had similar characteristics related to likelihood of having MMPI (Appendix 2).

In unadjusted comparisons, pessimists did not differ from non-pessimists with regards to key demographic and clinical covariates in primary THA cohort (Table 2). Pessimists were more likely to be younger than nonpessimists in the revision THA cohort (Table 2).

\section{Pessimistic explanatory style and outcomes 2-years after primary THA}

$12.3 \%$ of pessimists versus $8.6 \%$ of non-pessimists had moderate-severe pain 2-years after primary THA leading to an odds ratio of 2.16 (95 \% CI: $0.90,5.20 ; p=0.08$ ) in pessimists compared to non-pessimists in the multivariableadjusted logistic model (Table 3). $17.6 \%$ pessimists versus $12.7 \%$ non-pessimists reported lack of improvement of hip function to much better at 2-year follow up. Multivariableadjusted odds of lack of much better hip function improvement at 2-years were higher in pessimists, but not statistically significant, OR was 1.87 (95\% CI: $0.77,4.52 ; p=0.16$ ). $42.2 \%$ pessimists versus $32.4 \%$ non-pessimists reported moderate-severe activity limitation 2-years after primary THA, which was statistically significant, OR was 2.90 (95\% CI, 1.25, 6.70; $p=0.01$ ) (Table 3). Even when using an adjusted $p$-value threshold for multiple comparisons (three outcomes in this cohort, adjusted $p$-value of 0.017 ), this was statistically significant.

\section{Pessimistic explanatory style and outcomes 2-years after revision THA}

Pessimists were not significantly different than nonpessimists to report moderate-severe pain, lack of "much better" improvement in hip function or moderate-severe activity limitation 2 years post-revision THA, ORs were 1.18 (95 \% CI: 0.50, 2.81; $p=0.71$ ), 1.08 (95 \% CI: 0.52, $2.27 ; p=0.83$ ) and 1.73 (95\% CI: 0.76, 3.94; $p=0.19$ ), respectively (Table 4). 
Table 1 Demographic and clinical characteristics of the study cohort

\begin{tabular}{|c|c|c|c|}
\hline & $\begin{array}{l}\text { Primary THA 2-year } \\
(n=488)\end{array}$ & & $\begin{array}{l}\text { Revision THA 2-year } \\
(n=196)\end{array}$ \\
\hline Years from MMPI to surgery, median (range) & $16.6(0-41.3)$ & & $15.6(0.2-40.9)$ \\
\hline Age, Mean (SD) & $67.4(11.6)$ & & $67.8(11.5)$ \\
\hline$\%$ Men & $42.6 \%$ & & $46.9 \%$ \\
\hline Pessimists, $n(\%)$ & $124(25.4 \%)$ & & 66 (33.7 \%) \\
\hline T-score for depression, Mean (SD) & $56.8(11.1)$ & & $59.3(10.3)$ \\
\hline \multicolumn{4}{|l|}{ Age groups, $n(\%)$} \\
\hline$\leq 60$ years & $117(24 \%)$ & & $43(21.9 \%)$ \\
\hline $61-70$ years & $152(31.1 \%)$ & & $61(31.1 \%)$ \\
\hline $71+$ years & $219(44.9 \%)$ & & $92(46.9 \%)$ \\
\hline \multicolumn{4}{|l|}{ Body Mass index (in kg/m²), $n(\%)$} \\
\hline$\leq 25$ & $120(24.6 \%)$ & & $53(27 \%)$ \\
\hline$>25-29.9$ & $186(38.1 \%)$ & & 77 (39.3 \%) \\
\hline $30-34.9$ & $114(23.4 \%)$ & & $51(26 \%)$ \\
\hline $35-39.9$ & $42(8.6 \%)$ & & $6(3.1 \%)$ \\
\hline$\geq 40$ & $21(4.3 \%)$ & & $6(3.1 \%)$ \\
\hline Missing & $5(1 \%)$ & & $3(1.5 \%)$ \\
\hline \multicolumn{4}{|l|}{ ASA Score, $n(\%)$} \\
\hline Class I-II & $268(54.9 \%)$ & & 90 (45.9\%) \\
\hline Class III-IV & $220(45.1 \%)$ & & $106(54.1 \%)$ \\
\hline Charlson Index, Mean (SD) & $1.6(2.2)$ & & $1.4(2.1)$ \\
\hline Operative Diagnoses, $n$ (\%) & & Operative Diagnoses, n (\%) & \\
\hline $\begin{array}{l}\text { Rheumatoid Arthritis/ Other Inflammatory } \\
\text { arthritis conditions }\end{array}$ & $19(3.9 \%)$ & Loosening, Wear or Osteolysis & $146(74.5 \%)$ \\
\hline Osteoarthritis & $409(83.8 \%)$ & $\begin{array}{l}\text { Dislocation, Bone or Prosthesis Fracture, Instability, } \\
\text { Non-Union }\end{array}$ & $34(17.3 \%)$ \\
\hline Avascular necrosis & $48(9.8 \%)$ & $\begin{array}{l}\text { Failed Arthroplasty with Components Removed or } \\
\text { Infection }\end{array}$ & $16(8.2 \%)$ \\
\hline Other & $12(2.5 \%)$ & & \\
\hline Cemented Implant, $n$ (\%) & & & N/A \\
\hline Yes & $64(13.1 \%)$ & & \\
\hline Hybrid & $294(60.2 \%)$ & & \\
\hline No & $130(26.6 \%)$ & & \\
\hline
\end{tabular}

N/A Not applicable, ASA American Society of Anesthesiologists, SD standard deviation

\section{Discussion}

To our knowledge, this is the first study to examine the association between the preexisting psychological trait of a pessimistic explanatory style and PROs at intermediate post-operative follow-up in patients undergoing THA. We investigated intermediate-term PROs of selfreported pain, activity limitation and the lack of much better improvement in hip joint function. It is important to note that scores on the PSM scale used to classify our patients were obtained from MMPIs that had been completed a median of 16-17 years before their primary THA. The MMPI scores are valid, reliable and stable across several years $[18,20]$. Specifically, previous studies showed that MMPI scores have high internal consistency, test-retest reliability [18] and stability over 52 years [20]. Several study findings deserve further discussion and have important implications.

Our study found that pessimism was associated with statistically significantly higher odds of moderatesevere activity limitation at 2 -years in primary THA, a non-significant trend for moderate-severe pain and no statistically significant association with the lack of improvement in hip function to "much better" at 2years post-primary THA and, with respective odds of $2.90,2.16$ and $1.87(p=0.01,0.08$ and 0.16 respectively). The striking similarity of these odd ratios to 
Table 2 Univariate association of pessimism with selected patient characteristics

\begin{tabular}{|c|c|c|c|c|c|c|}
\hline & & imary THA & & & vision THA & \\
\hline & Not Pessimists & Pessimists & & Not Pessimists & Pessimists & \\
\hline & No $(N=328)$ & Yes $(N=113)$ & $p$ value & No $(N=112)$ & Yes $(N=60)$ & $p$ value \\
\hline Gender & & & $0.23^{\mathrm{a}}$ & & & $0.92^{a}$ \\
\hline Female & $182(55.5 \%)$ & 70 (61.9 \%) & & 57 (50.9 \%) & 31 (51.7 \%) & \\
\hline Male & $146(44.5 \%)$ & 43 (38.1 \%) & & 55 (49.1\%) & 29 (48.3\%) & \\
\hline Age Category & & & $0.09^{a}$ & & & $0.04^{\mathrm{a}}$ \\
\hline$\leq 60$ & 73 (22.3 \%) & 27 (23.9 \%) & & 15 (13.4\%) & 18 (30.0 \%) & \\
\hline $61-70$ & 93 (28.4\%) & 43 (38.1\%) & & 34 (30.4 \%) & 18 (30.0 \%) & \\
\hline $71-80$ & 120 (36.6 \%) & 36 (31.9\%) & & 51 (45.5 \%) & 17 (28.3\%) & \\
\hline$>80$ & 42 (12.8\%) & 7 (6.2 \%) & & 12 (10.7 \%) & 7 (11.7\%) & \\
\hline BMI Category & & & $0.91^{a}$ & & & $0.11^{\mathrm{a}}$ \\
\hline$<25$ & 82 (25.2 \%) & 27 (24.3\%) & & 39 (35.8 \%) & 12 (20.0\%) & \\
\hline $25-29.9$ & 129 (39.7 \%) & 42 (37.8 \%) & & 39 (35.8 \%) & 25 (41.7 \%) & \\
\hline $30-34.9$ & 76 (23.4 \%) & 27 (24.3\%) & & 27 (24.8\%) & 16 (26.7 \%) & \\
\hline $35-39.9$ & 27 (8.3 \%) & 9 (8.1\%) & & $2(1.8 \%)$ & $4(6.7 \%)$ & \\
\hline$\geq 40$ & $11(3.4 \%)$ & $6(5.4 \%)$ & & 2 (1.8\%) & $3(5.0 \%)$ & \\
\hline ASA Score & & & $0.38^{\mathrm{a}}$ & & & $0.25^{\mathrm{a}}$ \\
\hline $1-2$ & 187 (57.0 \%) & 59 (52.2 \%) & & 55 (49.1\%) & 24 (40.0\%) & \\
\hline $3-4$ & 141 (43.0 \%) & 54 (47.8 \%) & & 57 (50.9 \%) & 36 (60.0 \%) & \\
\hline Charlson Index & & & $0.47^{b}$ & & & $0.20^{\mathrm{b}}$ \\
\hline Mean (SD) & $0.3(0.4)$ & $0.3(0.5)$ & & $0.3(0.5)$ & $0.2(0.3)$ & \\
\hline Median (Q1, Q3) & $0.2(0,0.4)$ & $0.2(0,0.4)$ & & $0.2(0,0.4)$ & $0.2(0,0.4)$ & \\
\hline Income Category & & & $0.23^{\mathrm{a}}$ & & & $0.53^{\mathrm{a}}$ \\
\hline$<=\$ 35 \mathrm{~K}$ & 59 (21.1\%) & 22 (23.9 \%) & & 26 (28.6 \%) & 11 (22.4 \%) & \\
\hline$>\$ 35 K-\$ 45 K$ & 101 (36.2 \%) & 40 (43.5 \%) & & 46 (50.5 \%) & 24 (49.0\%) & \\
\hline$>\$ 45 \mathrm{~K}$ & 119 (42.7 \%) & 30 (32.6 \%) & & 19 (20.9\%) & 14 (28.6\%) & \\
\hline Distance Category & & & $0.10^{\mathrm{a}}$ & & & $0.91^{\mathrm{a}}$ \\
\hline 0-100 miles & $178(57.2 \%)$ & $61(59.2 \%)$ & & $44(41.9 \%)$ & $23(41.1 \%)$ & \\
\hline$>100-500$ miles & $104(33.4 \%)$ & 39 (37.9 \%) & & $45(42.9 \%)$ & $23(41.1 \%)$ & \\
\hline$>500$ miles or Non-US & $29(9.3 \%)$ & $3(2.9 \%)$ & & $16(15.2 \%)$ & $10(17.9 \%)$ & \\
\hline Operative Diagnosis & & & $0.11^{\mathrm{a}}$ & & & \\
\hline Inflammatory Arthritis & $12(3.7 \%)$ & $1(0.9 \%)$ & & & & \\
\hline Osteoarthritis & $278(84.8 \%)$ & $95(84.1 \%)$ & & & & \\
\hline AVN & $32(9.8 \%)$ & $11(9.7 \%)$ & & & & \\
\hline Other & $6(1.8 \%)$ & $6(5.3 \%)$ & & & & \\
\hline Loosening/Wear or Osteolysis & & & & $89(79.5 \%)$ & $39(65.0 \%)$ & $0.08^{\mathrm{a}}$ \\
\hline Dislocation, Bone or Prosthesis Fracture, Instability & & & & $17(15.2 \%)$ & $13(21.7 \%)$ & \\
\hline Failed arthroplasty with components removed or infection & & & & $6(5.4 \%)$ & $8(13.3 \%)$ & \\
\hline Cemented & & & $0.83^{\mathrm{a}}$ & & & N/A \\
\hline Yes & $44(13.4 \%)$ & $17(15.0 \%)$ & & & & \\
\hline Hybrid & $199(60.7 \%)$ & $65(57.5 \%)$ & & & & \\
\hline No & 85 (25.9\%) & $31(27.4 \%)$ & & & & \\
\hline Pre-operative Moderate/Severe Pain & & & $0.58^{\mathrm{a}}$ & & & $0.32^{\mathrm{a}}$ \\
\hline No & $9(4.2 \%)$ & $2(2.7 \%)$ & & $14(35.9 \%)$ & $6(24.0 \%)$ & \\
\hline
\end{tabular}


Table 2 Univariate association of pessimism with selected patient characteristics (Continued)

\begin{tabular}{|c|c|c|c|c|c|c|}
\hline Yes & $207(95.8 \%)$ & $71(97.3 \%)$ & & $25(64.1 \%)$ & $19(76.0 \%)$ & \\
\hline Pre-operative 3+ Moderate/Severe Activity Limitations & & & $0.22^{\mathrm{a}}$ & & & $0.45^{\mathrm{a}}$ \\
\hline No & $14(6.6 \%)$ & $2(2.7 \%)$ & & $9(23.1 \%)$ & $4(15.4 \%)$ & \\
\hline Yes & $199(93.4 \%)$ & $71(97.3 \%)$ & & $30(76.9 \%)$ & $22(84.6 \%)$ & \\
\hline
\end{tabular}

${ }^{\mathrm{a} C h i-S q u a r e ~ t e s t}$

${ }^{\mathrm{b}}$ Kruskal Wallis test

those noted previously in a primary TKA cohort, and the consistency of associations across univariate and multivariable-adjusted models, is supportive of these associations being real. Several reasons might explain poorer outcomes in pessimists: (1) Pessimists may be less resilient in adapting to the challenges of major surgery such as THA and this may impact their ability to successfully perform physical rehabilitation, as noted in patients with depression [25, 26], and ultimately their functional outcome; (2) pessimistic explanatory style may have had a negative influence on outcome expectation and lower patient expectation is associated with worse results and lower patient satisfaction after arthroplasty [27-31].

Our study findings have several important implications. First, this study identifies and informs patients and

Table 3 Multivariable-adjusted association ${ }^{\text {a }}$ of Pessimism with outcomes 2-years after Primary THA

\begin{tabular}{|c|c|c|c|}
\hline & $\mathrm{n} / \mathrm{N}^{\mathrm{b}}(\%)$ & OR $(95 \% \mathrm{Cl})$ & $p$-value \\
\hline \multicolumn{4}{|c|}{ Moderate-Severe Pain vs. None-Mild Pain } \\
\hline \multicolumn{4}{|c|}{ Pessimist } \\
\hline No & $27 / 339=8 \%$ & 1.0 & \\
\hline Yes & $14 / 114=12.3 \%$ & $2.16(0.90,5.20)^{c}$ & 0.08 \\
\hline
\end{tabular}

Improvement in Hip Function to "Better/Same/Worse" vs. "Much Better"

Pessimist

$$
\begin{array}{lllll}
\text { No } & 41 / 323=12.7 \% & 1.0 & & \\
\text { Yes } & 19 / 108=17.6 \% & 1.87(0.77,4.52)^{d} & 0.16
\end{array}
$$

Moderate-Severe Activity Limitation vs. None-Mild Activity Limitation

Pessimist

$$
\begin{array}{llll}
\text { No } & 110 / 340=32.4 \% & 1.0 & \\
\text { Yes } & 49 / 116=42.2 \% & \mathbf{2 . 9 0}(\mathbf{1 . 2 5}, \mathbf{6 . 7 0})^{\mathbf{e}} & \mathbf{0 . 0 1}
\end{array}
$$

Significant odds ratios are in bold; Numbers rounded to the nearest digit for percentages

${ }^{a}$ Multivariable logistic regression models adjusted for covariates consistent with 1 variable per 10 events rule. Variables were added in the following order due to clinical relevance: gender and age; depression; medical comorbidity; income; preoperative pain and function

${ }^{\mathrm{b}}$ Totals may not add up exactly to 488 at 2-years due to missing responses to each of the variable

' Model adjusted for age, sex, depression score (41 events)

${ }^{\mathrm{d}}$ Model adjusted for age, sex, depression score and Charlson index, since

adding income prevented the model from converging (60 events)

e Model adjusted for age, sex, depression score, Charlson index, income, preoperative pain and preoperative function (86 events) surgeons that pessimistic style is a novel risk factor for poor functional outcome after primary THA, in addition to previous known factors such as demographics (age, gender) and depression [22, 23]. Screening for pessimism in patients with other risk factors for poor outcomes may be indicated. Second, this knowledge can allow the surgeon and patients to have realistic expectations of outcomes following primary THA. Third, a cognitive-behavioral intervention may be appropriate to improve outcomes in patients with pessimistic explanatory style undergoing primary THA; this remains to be tested. These findings also add to the recent findings that pessimism is associated with poorer selfreported health in general medical [6], and cancer patients $[32,33]$, the success of smoking cessation among medical patients [34] and with mortality in medical outpatients [5] and in a college sample [35].

Table 4 Multivariable-adjusted association ${ }^{\mathrm{a}}$ of Pessimism with outcomes 2-years after Revision THA

\begin{tabular}{llll}
\hline & $\mathrm{n} / \mathrm{N}^{\mathrm{b}}(\%)$ & OR $(95 \% \mathrm{Cl})$ & $p$-value \\
\hline $\begin{array}{c}\text { Moderate-Severe Pain vs. None-Mild Pain } \\
\text { Pessimist }\end{array}$ & & & \\
No & $28 / 123=22.8 \%$ & & \\
Yes & $17 / 66=25.8 \%$ & $1.18(0.50,2.81)^{c}$ & 0.71
\end{tabular}

Improvement in Hip Function to "Better/Same/Worse" vs. "Much Better" Pessimist

$$
\begin{array}{llll}
\text { No } & 38 / 110=34.5 \% & 1.0 \\
\text { Yes } & 22 / 59=37.3 \% & 1.08(0.52,2.27)^{d} & 0.83
\end{array}
$$

Moderate-Severe Activity Limitation vs. None-Mild Activity Limitation

$$
\text { Pessimist }
$$

$\begin{array}{lll}\text { No } & 67 / 123=54.5 \% & 1.0 \\ \text { Yes } & 42 / 63=66.7 \% & 1.73(0.76,3.94)^{\text {e }} \quad 0.19\end{array}$

${ }^{a}$ Multivariable logistic regression models adjusted for covariates consistent with 1 variable per 10 events rule. Variables were added in the following order due to clinical relevance: gender and age; depression; medical comorbidity; income; preoperative pain and function

${ }^{\mathrm{b}}$ Totals may not add up exactly to 196 at 2-years due to missing responses to each of the variable

${ }^{c}$ Model adjusted for age, sex, depression score (45 events)

d Model adjusted for age, sex, depression score and Charlson index; adding income prevents the model from converging (60 events)

e Model adjusted for age, sex, depression score, Charlson index, and income (85 events; no other variables had univariate $p$-values less than 0.2 ) 
Pessimistic style was associated with numerically higher odds of moderate-severe pain, but this did not reach statistical significance in multivariable-adjusted models. The odds of moderate-severe pain of 2.16 (95\% CI, 0.90, 5.20; $p=0.08$ ) between pessimism and moderate-severe pain 2years after primary THA in the present study is similar to the previously reported statistically significant odds ratio of $2.21(95 \% \mathrm{CI}, 1.12,4.35 ; p=0.02)$ for pessimism and moderate-severe pain 2-years after primary TKA cohort [4]. Importantly, the direction and magnitude of association is similar to that noted in the previous study for a TKS cohort. It is possible that the association of pessimism with moderate-severe pain may be weaker after THA vs. TKA; however, the similarity of odds ratio indicates this was likely not the case. A more likely explanation is that the association in primary THA failed to reach statistical significance due to a smaller sample size in the present study, with our current study consisted of 488 patients with only 41 patients with reporting moderate-severe pain (outcome of interest) in our current THA study versus compared to 783 patients with 87 patients with reporting moderate-severe pain (outcome of interest) in the previous TKA study [4].

We noted that the magnitude of associations of pessimistic style with poorer functional and pain outcomes in patients undergoing revision THA (OR ranging 1.08 to 1.73) was much weaker to non-existent. This finding indicates that the pathways to pain and function outcomes after revision THA are likely different than those after primary THA. The lack of significance may at least partially be due to a smaller sample size than primary THA (202 vs. 507 patients).

These study findings must be interpreted considering study limitations. First, the patients chosen by the physicians and asked to complete an MMPI were not chosen at random. However, this bias mirrors clinical practice, which improves generalizability of findings, where only patients suspected to have psychological distress would be referred for such an evaluations. This tool can't and shouldn't be administered to all-comers for THA, due to the length of the survey and the low prevalence of pessimistic explanatory style. Explanatory style is unlikely to have biased completion and return rates for the MMPIs among the medical outpatients included in our study, as reported previously [36]. Our study was completed entirely with the original version of the MMPI. For clinicians or researchers interested in replicating or disputing our findings, a revised version of the PSM scale, the PSM-R [19] has been developed for the MMPI-2, the current version of the original MMPI. Less than $1 \%$ THA were bilateral, and we used GEE to account for correlated observations. Residual confounding due to other known and unknown variables is another potential limitation given that the observational study design. All study outcomes were PROs that are self-reported.
However PROs are widely accepted as the most important outcomes after an elective surgery such as THA. The long-time lag between MMPI profile and THA does not threaten the validity of these findings, since Seligman's theory postulates pessimism to be an enduring trait, one that has been validated among medical outpatients over a 30-year follow up [5, 6].

Some of the patients studied underwent THA 20 years ago, which should be considered while interpreting findings. However, while some changes in surgical techniques or implants have occurred, we are not aware of any data demonstrating strong upwards or downwards trends in patient-reported outcomes in the last two decades. Therefore, the findings presented here are likely relevant to current THA patient populations. We used a single-item pain question rather than a multi-item questionnaire such as Western Ontario McMaster Osteoarthritis Index (WOMAC) or Knee Osteoarthritis Outcome Score (KOOS). Potential disadvantage of using a single-item are that longer instruments (WOMAC, KOOS) are more validated. Advantages of a single-item pain assessment are the feasibility of administering a single-item in a busy clinical practice or even in research settings, which likely improves response rate and generalizability of findings. Pain as the fifth vital sign has always been assessed as a single question in routine clinical settings in the U.S. for years, not with multi-item scales. In addition, the summated scores may not always superior to a single item assessment scale [37].

Our study has several strengths. Study sample size was relatively large, validated patient-relevant outcomes were used, both primary and revision THA populations were studied and we performed multivariable-adjusted analyses including important covariates.

\section{Conclusions}

In conclusion, we found that a pessimistic explanatory style before surgery was associated with significantly less favorable improvement in function/ activity limitation after primary THA and possibly higher risk of moderate-severe pain. Screening for patients suspected to be at risk (pessimists) may be indicated, based on clinical suspicion. In those with known pessimistic explanatory style, screening for other risk factors for poorer PRO outcomes post-primary THA may be indicated. Psycho-educational and cognitive- behavioral strategies may be evaluated for pessimists undergoing elective primary THA.

\section{Data availability}

These data will be made available to other researchers upon request, after meeting appropriate data privacy and Human subject protection requirements, as per institutional requirements. 


\section{Appendix}

Table 5 Responders to MMPI survey 2-year follow-up for Primary THA

\begin{tabular}{|c|c|c|c|c|c|c|c|}
\hline Total Obs & Yes Events & Variable & Level & Yes Events/Trials & Odds Ratio & 95\% Cl for Odds Ratio & $p$-value \\
\hline \multirow[t]{2}{*}{5707} & 488 & Gender & Female & $280 / 2929=9.6 \%$ & & & \\
\hline & & & Male & $208 / 2778=7.5 \%$ & 0.77 & $(0.62,0.94)$ & 0.01 \\
\hline \multirow[t]{4}{*}{5707} & 488 & Age Category & $\leq 60$ & $117 / 1730=6.8 \%$ & & & \\
\hline & & & $61-70$ & $152 / 1759=8.6 \%$ & 1.30 & $(0.99,1.72)$ & 0.06 \\
\hline & & & $71-80$ & $169 / 1721=9.8 \%$ & 1.50 & $(1.15,1.97)$ & $<0.01$ \\
\hline & & & $>80$ & $50 / 497=10.1 \%$ & 1.54 & $(1.07,2.23)$ & 0.02 \\
\hline \multirow[t]{5}{*}{5679} & 483 & BMI Category & $<25$ & $120 / 1387=8.7 \%$ & & & \\
\hline & & & $25-29.9$ & $186 / 2224=8.4 \%$ & 0.96 & $(0.75,1.24)$ & 0.78 \\
\hline & & & $30-34.9$ & $114 / 1361=8.4 \%$ & 0.97 & $(0.72,1.29)$ & 0.81 \\
\hline & & & $35-39.9$ & $42 / 479=8.8 \%$ & 1.01 & $(0.68,1.51)$ & 0.94 \\
\hline & & & $\geq 40$ & $21 / 228=9.2 \%$ & 1.07 & $(0.62,1.85)$ & 0.81 \\
\hline \multirow[t]{2}{*}{5678} & 488 & ASA Score & $1-2$ & $268 / 3540=7.6 \%$ & & & \\
\hline & & & $3-4$ & $220 / 2138=10.3 \%$ & 1.40 & $(1.16,1.70)$ & $<0.01$ \\
\hline 5701 & 488 & Charlson Index (5 point increase) & N/A & N/A & 1.76 & $(1.44,2.14)$ & $<0.01$ \\
\hline \multirow[t]{3}{*}{4792} & 412 & Income Category & $>\$ 45 K$ & $167 / 1507=11.1 \%$ & & & \\
\hline & & & $\leq \$ 35 K$ & $91 / 1234=7.4 \%$ & 0.64 & $(0.48,0.85)$ & $<0.01$ \\
\hline & & & $>\$ 35 K-\$ 45 K$ & $154 / 2051=7.5 \%$ & 0.65 & $(0.51,0.83)$ & $<0.01$ \\
\hline \multirow[t]{3}{*}{5511} & 459 & Distance Category & 0-100 miles & $266 / 2664=10 \%$ & & & \\
\hline & & & $>100-500$ miles & $155 / 2280=6.8 \%$ & 0.66 & $(0.53,0.82)$ & $<0.01$ \\
\hline & & & $>500$ miles or Non-US & $38 / 567=6.7 \%$ & 0.65 & $(0.44,0.95)$ & 0.03 \\
\hline \multirow[t]{4}{*}{5707} & 488 & Operative Diagnosis & Inflammatory Arthritis & $19 / 148=12.8 \%$ & & & \\
\hline & & & AVN & $48 / 409=11.7 \%$ & 0.90 & $(0.47,1.73)$ & 0.76 \\
\hline & & & Osteoarthritis & $409 / 4944=8.3 \%$ & 0.61 & $(0.34,1.09)$ & 0.09 \\
\hline & & & Other & $12 / 206=5.8 \%$ & 0.42 & $(0.19,0.95)$ & 0.04 \\
\hline
\end{tabular}

Table 6 Responders to MMPI survey 2-year follow-up for Revision THA

\begin{tabular}{|c|c|c|c|c|c|c|c|}
\hline $\begin{array}{l}\text { Total } \\
\text { Obs }\end{array}$ & $\begin{array}{l}\text { Yes } \\
\text { Events }\end{array}$ & Variable & Level & $\begin{array}{l}\text { Yes Events/ } \\
\text { Trials }\end{array}$ & $\begin{array}{l}\text { Odds } \\
\text { Ratio }\end{array}$ & $\begin{array}{l}95 \% \text { Cl for Odds } \\
\text { Ratio }\end{array}$ & $p$-value \\
\hline \multirow[t]{2}{*}{2687} & 196 & Gender & Female & $104 / 1437=7.2 \%$ & & & \\
\hline & & & Male & $92 / 1250=7.4 \%$ & 1.02 & $(0.74,1.41)$ & 0.91 \\
\hline \multirow[t]{4}{*}{2687} & 196 & Age Category & $\leq 60$ & $43 / 796=5.4 \%$ & & & \\
\hline & & & $61-70$ & $61 / 731=8.3 \%$ & 1.59 & $(1.03,2.48)$ & 0.04 \\
\hline & & & $71-80$ & $71 / 902=7.9 \%$ & 1.50 & $(0.97,2.32)$ & 0.07 \\
\hline & & & $>80$ & $21 / 258=8.1 \%$ & 1.55 & $(0.86,2.79)$ & 0.14 \\
\hline \multirow[t]{5}{*}{2652} & 193 & BMI Category & $<25$ & $53 / 777=6.8 \%$ & & & \\
\hline & & & $25-29.9$ & $77 / 1024=7.5 \%$ & 1.11 & $(0.77,1.61)$ & 0.58 \\
\hline & & & $30-34.9$ & $51 / 576=8.9 \%$ & 1.33 & $(0.87,2.04)$ & 0.19 \\
\hline & & & $35-39.9$ & $6 / 183=3.3 \%$ & 0.46 & $(0.20,1.10)$ & 0.08 \\
\hline & & & $\geq 40$ & $6 / 92=6.5 \%$ & 0.95 & $(0.35,2.57)$ & 0.92 \\
\hline \multirow[t]{2}{*}{2679} & 196 & ASA Score & $1-2$ & $90 / 1384=6.5 \%$ & & & \\
\hline & & & $3-4$ & $106 / 1295=8.2 \%$ & 1.28 & $(0.95,1.73)$ & 0.10 \\
\hline 2682 & 196 & Charlson Index (5 point increase) & N/A & N/A & 2.23 & $(1.60,3.11)$ & $<0.01$ \\
\hline 2049 & 157 & Income Category & $>\$ 45 K$ & $37 / 480=7.7 \%$ & & & \\
\hline
\end{tabular}


Table 6 Responders to MMPI survey 2-year follow-up for Revision THA (Continued)

\begin{tabular}{|c|c|c|c|c|c|c|c|}
\hline & & & $\leq \$ 35 K$ & $41 / 604=6.8 \%$ & 0.87 & $(0.54,1.41)$ & 0.58 \\
\hline & & & $>\$ 35 K-\$ 45 K$ & $79 / 965=8.2 \%$ & 1.07 & $(0.70,1.63)$ & 0.76 \\
\hline \multirow[t]{3}{*}{2575} & 184 & Distance Category & 0-100 miles & $77 / 829=9.3 \%$ & & & \\
\hline & & & $>100-500$ miles & $77 / 1426=5.4 \%$ & 0.56 & $(0.39,0.80)$ & $<0.01$ \\
\hline & & & $>500$ miles or Non-US & $30 / 320=9.4 \%$ & 1.01 & $(0.62,1.65)$ & 0.97 \\
\hline \multirow[t]{3}{*}{2687} & 196 & Operative Diagnosis & Loosening/Wear or Osteolysis & $146 / 1959=7.5 \%$ & & & \\
\hline & & & $\begin{array}{l}\text { Dislocation, Bone or Prosthesis } \\
\text { Fracture, Instability, Non-Union }\end{array}$ & $34 / 447=7.6 \%$ & 1.02 & $(0.69,1.52)$ & 0.91 \\
\hline & & & $\begin{array}{l}\text { Failed Prior Arthroplasty with } \\
\text { Components Removed or Infection }\end{array}$ & $16 / 281=5.7 \%$ & 0.75 & $(0.43,1.32)$ & 0.32 \\
\hline
\end{tabular}

\section{Abbreviations}

ASA: American society of anesthesiology; BMI: Body mass index;

Cl: confidence interval; MMPI: Minnesota multiphasic personality inventory; OR: odds ratio; PROs: patient-reported outcomes; PSM: Optimism-pessimism scale; THA: total hip arthroplasty.

\section{Competing interests}

JAS has received research and travel grants from Takeda and Savient; and consultant fees from Savient, Takeda, Regeneron, Iroko, Merz, Bioiberica, Crealta and Allergan pharmaceuticals, WebMD, UBM LLC and the American College of Rheumatology. DGL has received royalties/speaker fees from Zimmer, institutional research funds from DePuy, Stryker and Zimmer and has been a paid consultant to Zimmer. All other authors have no competing interested to declare.

\section{Authors' contributions}

JAS was responsible for study conception and design, development of study protocol methods and analyses, review of statistical analyses and drafting of first version of the manuscript. DGL was responsible for review and revision of study design and study protocol, and review of statistical analyses. $\mathrm{MO}$ performed and reviewed the analyses. RC reviewed the analyses. All authors critically revised the paper and approved the final version of the paper.

\section{Acknowledgements}

We thank Youlonda Loechler of the Mayo Clinic for assistance in data extraction and Scott Harmsen for statistical advice and programming. This study was supported by the research funds from the Department of Orthopedic Surgery, Mayo Clinic School of Medicine, Rochester, MN. "The views expressed in this article are those of the authors and do not necessarily reflect the position or policy of the Department of Veterans Affairs or the United States government."

Each author certifies that his or her institution has approved the human protocol for this investigation and that all investigations were conducted in conformity with ethical principles of research. The authors take full responsibility for the data analysis and presentation.

\section{Author details}

'Department of Orthopedic Surgery, Mayo Clinic, Rochester, MN, USA

2Department of Psychiatry and Psychology, Mayo Clinic, Rochester, MN, USA. ${ }^{3}$ Department of Health Sciences Research, Mayo Clinic, Rochester, MN, USA. ${ }^{4}$ Rheumatology Section, Medicine Service, VA Medical Center, Minneapolis, MN, USA. ${ }^{5}$ Division of Rheumatology, Department of Medicine, University of Alabama at Birmingham (UAB), Birmingham, AL 35294, USA. ${ }^{6}$ University of Alabama, Faculty Office Tower, 805B, 510 20th Street S, Birmingham, AL 35294, USA.

\section{Received: 30 December 2015 Accepted: 22 April 2016} Published online: 04 May 2016

\section{References}

1. NIH Consensus Panel. NIH Consensus Statement on total knee replacement December 8-10, 2003. J Bone Joint Surg Am. 2004;86-A(6):1328-35.

2. Kane RL, Saleh KJ, Wilt TJ, Bershadsky B. The functional outcomes of total knee arthroplasty. J Bone Joint Surg Am. 2005;87(8):1719-24.
3. Ayers DC, Franklin PD, Ploutz-Snyder R, Boisvert CB. Total knee replacement outcome and coexisting physical and emotional illness. Clin Orthop Relat Res. 2005;440:157-61.

4. Singh JA, O'Byrne MM, Colligan RC, Lewallen DG. Pessimistic explanatory style: a psychological risk factor for poor pain and functional outcomes two years after knee replacement. J Bone Joint Surg (Br). 2010;92(6):799-806.

5. Maruta T, Colligan RC, Malinchoc M, Offord KP. Optimists vs pessimists: survival rate among medical patients over a 30-year period. Mayo Clin Proc. 2000;75(2):140-3.

6. Maruta T, Colligan RC, Malinchoc M, Offord KP. Optimism-pessimism assessed in the 1960s and self-reported health status 30 years later. Mayo Clin Proc. 2002;77(8):748-53.

7. Gillham JE, Shatte AJ, Reivich KJ, Seligman ME. Optimism, Pessimism, and Explanatory Style. In: Chang E, editor. Optimism \& Pessimism: Implications for Theory, Research, and Practice. Washington, D.C.: American Psychiatric Association; 2001. p. 53-76.

8. Seligman M. Explanatory style: predicting depression, achievement, and health. In: Yapko M, editor. Brief Therapy Approaches to Treating Anxiety and Depression. New York: Brunner/Maze; 1989.

9. Seligman M, Kaman L, Nolan-Hoeksema S. Explanatory Style across the Life Span: Achievement and health. In: Hetherington E, editor. Child Development in Life span Perspective. Hillsdale: Erlbaum; 1988. p. 91-114.

10. Peterson C, Bossio LM. Optimism and Physical Well-Being. In: Chang EC, editor. Optimism \& Pessimism: Implications for Theory, Research, and Practice. Washington, D.C.: American Psychiatric Association; 2001. p. 127-45.

11. Balck F, Lippmann M, Jeszenszky C, Gunther KP, Kirschner S. The influence of optimism on functionality after total hip replacement surgery. J Health Psychol. 2015. pii: 1359105314566256. [Epub ahead of print].

12. McGrory BJ, Morrey BF, Rand JA, Ilstrup DM. Correlation of patient questionnaire responses and physician history in grading clinical outcome following hip and knee arthroplasty. A prospective study of 201 joint arthroplasties. J Arthroplasty. 1996;11(1):47-57.

13. Kavanagh BF, Fitzgerald Jr RH. Clinical and roentgenographic assessment of total hip arthroplasty. A new hip score Clin Orthop Relat Res. 1985:193:133-40.

14. STROBE Statement. Strengthening the reporting of observational studies in epidemiology. Link: http://www.strobe-statement.org/fileadmin/Strobe/ uploads/checklists/STROBE_checklist_v4_cohort.pdf. Accessed 27Apr. 2016.

15. Butcher J, Dahlstrom W, Graham J, Tellegen A, Kaemmer B. Manual for Administration and Scoring: MMPI-2, Minnesota Multiphasic Personality Inventory-2 (Revised Edition). Minneapolis: University of Minnesota Press; 2001.

16. Butcher JN. A Beginner's Guide to the MMPI-2. Washington D.C.: American Psychological Association; 2005.

17. Hathaway S, McKinley J. The Minnesota Multiphasic Personality Inventory. Revth ed. Minneapolis: University of Minnesota Press; 1943.

18. Colligan RC, Offord KP, Malinchoc M, Schulman P, Seligman ME. CAVEing the MMPI for an Optimism-Pessimism Scale: Seligman's attributional model and the assessment of explanatory style. J Clin Psychol. 1994;50(1):71-95.

19. Malinchoc M, Offord KP, Colligan RC. PSM-R: Revised Optimism-Pessimism Scale for the MMPI-2 and MMPI. J Clin Psychol. 1995:51(2):205-14.

20. Burns MO, Seligman ME. Explanatory style across the life span: evidence for stability over 52 years. J Pers Soc Psychol. 1989;56(3):471-7.

21. Singh JA, Lewallen DG. Predictors of activity limitation and dependence on walking aids after primary total hip arthroplasty. J Am Geriatr Soc. 2010; 58(12):2387-93. 
22. Singh JA, Lewallen D. Age, gender, obesity, and depression are associated with patient-related pain and function outcome after revision total hip arthroplasty. Clin Rheumatol. 2009;28(12):1419-30.

23. Singh $J A$, Lewallen $D$. Predictors of pain and use of pain medications following primary Total Hip Arthroplasty (THA): 5,707 THAs at 2-years and 3,289 THAs at 5-years. BMC Musculoskelet Disord. 2010;11:90.

24. Holtzman J, Saleh K, Kane R. Gender differences in functional status and pain in a Medicare population undergoing elective total hip arthroplasty. Med Care. 2002:40(6):461-70.

25. McGrady A, McGinnis R, Badenhop D, Bentle M, Rajput M. Effects of depression and anxiety on adherence to cardiac rehabilitation. J Cardiopulm Rehabil Prev. 2009;29(6):358-64.

26. Glazer KM, Emery CF, Frid DJ, Banyasz RE. Psychological predictors of adherence and outcomes among patients in cardiac rehabilitation. J Cardiopulm Rehabil Prev. 2002:22(1):40-6.

27. Gandhi R, Davey JR, Mahomed N. Patient Expectations Predict Greater Pain Relief with Joint Arthroplasty. J Arthroplasty. 2009;24(5):716-21. doi:10.1016/j. arth.2008.05.016

28. Noble PC, Conditt MA, Cook KF, Mathis KB. The John Insall Award: Patient expectations affect satisfaction with total knee arthroplasty. Clin Orthop Relat Res. 2006;452:35-43.

29. Eisler T, Svensson O, Tengstrom A, Elmstedt E. Patient expectation and satisfaction in revision total hip arthroplasty. J Arthroplasty. 2002;17(4):457-62.

30. Mahomed NN, Liang MH, Cook EF, Daltroy LH, Fortin PR, Fossel AH, Katz JN. The importance of patient expectations in predicting functional outcomes after total joint arthroplasty. J Rheumatol. 2002;29(6):1273-9.

31. Haddad FS, Garbuz DS, Chambers GK, Jagpal TJ, Masri BA, Duncan CP. The expectations of patients undergoing revision hip arthroplasty. J Arthroplasty. 2001;16(1):87-91.

32. Kung S, Rummans $T A$, Colligan RC, Clark MM, Sloan JA, Novotny PJ, Huntington JL. Association of optimism-pessimism with quality of life in patients with head and neck and thyroid cancers. Mayo Clin Proc. 2006; 81(12):1545-52.

33. Petersen LR, Clark MM, Novotny P, Kung S, Sloan JA, Patten CA, Vickers KS, Rummans TA, Frost MH, Colligan RC. Relationship of optimism-pessimism and health-related quality of life in breast cancer survivors. J Psychosoc Oncol. 2008;26(4):15-32.

34. Ames SC, Vickers KS, Decker PA, Patten CA, Colligan RC, Vargas-Chanes D, Schroeder D, Offord KP. Select Minnesota Multiphasic Personality Inventory (MMPI) Scales as Predictors of Tobacco Abstinence Following Treatment for Nicotine Dependence. Psychol Health. 2005;20:331-51.

35. Brummett BH, Helms MJ, Dahlstrom WG, Siegler IC. Prediction of all-cause mortality by the Minnesota Multiphasic Personality Inventory OptimismPessimism Scale scores: study of a college sample during a 40-year followup period. Mayo Clin Proc. 2006;81(12):1541-4.

36. McLeod TG, Costello BA, Colligan RC, Dierkhising RA, Beebe TJ, Offord KP, Locke GR, 3rd. Personality characteristics of health care satisfaction survey non-respondents. Int J Health Care Qual Assur. 2009:22(2):145-56.

37. Sloan JA, Aaronson N, Cappelleri JC, Fairclough DL, Varricchio C. Assessing the clinical significance of single items relative to summated scores. Mayo Clin Proc. 2002;77(5):479-87.

\section{Submit your next manuscript to BioMed Central and we will help you at every step:}

- We accept pre-submission inquiries

- Our selector tool helps you to find the most relevant journal

- We provide round the clock customer support

- Convenient online submission

- Thorough peer review

- Inclusion in PubMed and all major indexing services

- Maximum visibility for your research

Submit your manuscript at www.biomedcentral.com/submit
Biomed Central 